\title{
Research on the Challenges and Strategies of Building a Service Government in the Big Data Era
}

\author{
Yongmei Fu \\ Xi'an Peihua University, Xi'an, Shanxi Province, 710125
}

Keywords: Challenges, Strategies, Service Government, Big Data Era

\begin{abstract}
The construction of government public service system is an important part of building a service-oriented government. The advent of the big data era has brought opportunities and challenges to the improvement of government management and public service capabilities in China. The traditional service management model based on government as the center of power can no longer meet the needs of the public in providing information and services to public services in the information age. Therefore, the government should make full use of big data to build a public service system platform to make up for the deficiencies of the original government administration and service provision to a certain extent, so as to enhance the government's public service capability and remold service-oriented government image.
\end{abstract}

\section{Introduction}

The explosive growth of mobile terminals, social networks and the Internet of Things and the realization of cloud computing have given birth to "Big Data" as the era in which businesses in all fields of the world use and exploit vast data resources for economic, Social and cultural aspects of the great potential value of the target means.

In the era of big data, public data will be aggregated to the cloud, filtering at the middle level will be reduced, and information flow will be more open and free. This will make the government departments and the public more able to acquire and utilize information more symmetrically, and will be conducive to promoting democratic government decision-making. As far as the government is concerned, after the era of big data, the transformation of government functions is accelerating. The decision-making process of the government is not only from the top-down manner led by the power level within the department, but also relies more on big data collection and analysis as decision-making support, which has promoted the sharp increase in the accuracy and extensiveness of government decision-making and effectively avoided economic losses and social problems caused by the waste of government decision-making costs and mistakes in decision-making [1].

\section{The Status of Service-oriented Government in Big Data Era}

Expand the public service object a wide range of communication channels. At present, for our country, the government is still the main body of public service supply. In many cases, public services provided by government departments often come from the inertia of internal policies and their own inherent basic conditions, and still use the more traditional or semi-networked, half Automated platform channels to provide services, which makes the public access to the service blocked cannot be timely and effective access to services, while the public lacks an effective feedback mechanism, as the service providers and government departments is difficult to timely and accurate collection of the public Suggestions, identify the needs of positioning and service adjustments. In the era of big data, the construction of public service e-government system provides diversified channels for clients. At the same time, based on the data mining and analysis, it is possible to provide the public with personalized and customized service needs. The public can pass big data generalization of the application platform, to understand and obtain the information and services needed, and also for information consultation and feedback. And as a government department can also extract the analysis of the collected data to better predict and make decisions. 
Speed up the update and integration of public service information resources. At present, due to the solidification of the traditional government management concept and the lack of competition mechanism, government departments have been in a passive state of affairs, extensive affairs management and service provision for a long time [2]. The internal information and public feedback data are merely stored and become a lot of " Zombie data ", the lack of screening, classification and integration of information, not to mention the use of information mining and follow-up management decisions, information utilization is very low. The national "Internet +" general train of thought and the implementation of the government's goal of opening big data, the non-causal relationship between the public service class data, through the establishment of the relevant information infrastructure platform, to ensure the authority of the government's basic data and data security Sexual interoperability and integration under the premise of access, which makes not only public service information, but also includes the population, public security, health, social security and other government information resources on a unified platform for entry, to maximize data utilization and mining, at the same time Accelerate the formation of a mechanism for the government to speed up the integration of information resources based on the data content and data structure.

Increase the extent of the democratization of public service decisions. Information is formed on the basis of data extraction and scouring. The more diversified sources of information for the general public, the more diversified channels of information dissemination, the more diversified modes of participation, and the higher the degree of openness of the entire society. In the era of big data, the public can widely express policy suggestions through a variety of carrier-based data and information, and can make personalized content requirements for public services. The downward movement and proliferation of such centers of power have led to more and more public participation in the process of promoting the open government. At the same time, government departments, as the main body of public service provision, should respond positively to the public political demands brought by the promotion of big data. At the same time, the public feedback of information data through scientific and technological means should be integrated and analyzed to form the most suitable Public service policy recommendations, to promote the process of democratization of decision-making.

\section{The Challenges of the Service-oriented Government Construction in the Era of Big Data}

\subsection{Information Security Issues}

Information security is the prerequisite and guarantee for the government to provide the public with open information, excellent service and effectively perform the functions of the government under the era of big data. However, the related technologies of big data accelerate the collection of data with different data types, different storage media and different value densities, which inevitably increases the risk of users' leakage of private information. At the same time, government departments hold a large amount of public personal information, which can be tapped and exploited to create potential commercial value. This has led to the rise of profit-driven network hackers and the emergence of organizations that sell and buy public information, Information theft, information trafficking, information use of the black industrial chain, the government public service information resources system poses a great threat [3].

\subsection{Standard Specification Issues}

The standards and norms of relevant policies, systems and technologies formulated at the local government level are scattered at the local government level and are often based on the consideration of local localization, which leads to the non-uniform standard of public service relying on big data and the difficulty in forming a national-level The overall development together. In the meantime, the phenomenon of "re-establishing light applications and heavy hardware and software", "weakening in strength and strength" and "isolated islands of information" among local governments during the construction process has become more serious. As a result, platform construction of public services based on big data often appears within departments As a result, there 
is no clear agreement on the use of big data and the poor public service capability of the government. Therefore, under the unified planning and standards, how to integrate existing resources, prevent duplication and fragmentation, and become the key to building and developing the public service system based on the big data.

\subsection{Platform Construction Problems}

At present, in some local public service agencies, the phenomenon of chasing after the trend and hitting the trend often appears in the process of implementing the construction of a big data platform. As soon as the implementation of the national big data implementation policy is introduced and copied directly, the actual situation in the region is not fully taken into account. Reasonably consider its feasibility, resulting in a great waste of manpower and material resources. Some local governments, even though they have set up a public service platform based on big data, provide a single service with limited scope and lagging information to meet the public's real needs for public services. In addition, some local governments and departments are also excessively pursuing the advocacy of big data on the economic value generated by public services and developing the information platform from the viewpoint of "technological determinism", without paying attention to the construction of public service system and the system norms , personnel training and other aspects of construction, making the big data platform has become the government's "image project", officials of the "performance project."

\section{Strategy for Service-oriented Government Construction in Big Data Era}

Improve local infrastructure construction and improve the coordination of public service resources. The uneven development of government service agencies at all levels has led to the sluggish and uneven network infrastructure construction of some municipal and sub-county agencies, making it extremely difficult to build a fully covered public service platform and making it impossible for first-level government departments to utilize large The advantages of data to provide targeted services to the public. Therefore, improving local infrastructure as a prerequisite for building a platform for public service under the government's big data strategy is urgent. At all levels of government departments should pay attention to local infrastructure, not only to increase investment in manpower, material and financial resources in the construction of hardware facilities, but also to consider the "one construction, multiple use" economic cost analysis as the principle, To establish an infrastructure platform with high performance and low cost, we should also pay attention to the training of staff with relevant professional skills, strengthen the maintenance and management of infrastructure facilities, and effectively guarantee that the government can use big data to enhance public service capabilities [4].

Division of service business types, to strengthen the provision of public services targeted. Based on the principle of combining government functions with the analysis of public demand based on big data, the scope of business that is actually oriented to public service management is clearly defined and divided. First of all, senior decision-makers, grass-roots workers, appointed experts and scholars and public service representatives of relevant departments of public service functions should hold coordination seminars on a regular basis to listen to the opinions and suggestions of all levels of people on a regular basis. With economic, efficiency, effectiveness and other aspects For the evaluation criteria, selected online service issues, and then take a gradual way to gradually expand the scope. Secondly, to develop a relevant evaluation system to evaluate the services moved to the network. The data source for evaluation can collect feedback through the big data information of the public service platform. If the evaluation result is high, the public service business continues to be refined. The evaluation score Low service business can analyze the reasons for innovation in working methods, business process reengineering and other improvements. In addition, internal supervision and accountability should be exercised over the government service personnel and strict administrative accountability system should be adopted for ultra vires. Once service departments and their service personnel have committed these "high-voltage lines", the relevant accountability authority should start the accountability process immediately. 
Develop relevant policies and regulations to protect the orderly supply of public services. Establishing the concept of rule by law is the cornerstone of modern society and an important guarantee for maintaining the normal operation of society and promoting the harmonious, stable development of society. However, on the whole, the authoritativeness and effectiveness of the relevant policies and regulations on the basis of the provision of public service capability based on big data are slightly inadequate. The stability and lag of laws cannot be effectively and timely brought to the actual needs and sudden problems. Therefore, in the formulation and implementation of the relevant policies and regulations, we should first establish a systematic, holistic and hierarchical understanding of the construction of policies and regulations. The formulation of policies and regulations does not specify a certain aspect but the state and local institutions And technology, internal and external and many other levels, only continue to strengthen the convergence of these levels of policies and regulations in order to enhance the legal effectiveness of the system as a whole. Second, the formulation of relevant policies and regulations should be based on the full investigation of public opinion, combined with the actual conditions of national and local big data-related technologies and the level of public service capability and at the same time cover the areas of related fields to show accuracy. It includes information technology, information networks, information markets, information resources, information industry, information professionals and information standardization and internationalization and so on. Finally, the guiding principles of policies and regulations should be based on the audience, the implementation process, the effect of implementation of the emphasis on diversity, both should be guided, promote, but also punitive, prohibitive [5].

Improve the construction of information platform to expand the diversity of public service channels. In the era of big data, the government through the improvement of relevant information platform to enhance the government's public service capabilities, the specific practices are: First of all, in the platform display, should integrate and optimize the government public service business system all kinds of big data resources, the establishment of a Government unified government information platform to strengthen the authority and convenience to provide public service capabilities, the public can use the network terminal equipment, especially mobile terminals to quickly access information and services, timely interaction. Secondly, on the internal operation of the information platform set up by the government, it is necessary to make full use of big data to effectively solve the problems such as the independent operation of the service terminals, the lag of information and the dispersion of data, and strengthen the information disclosure and content construction of the government affairs platform so as to enhance the breadth of information utilization Timely and comprehensively release the resource information of the hot issues that are closely related to the vital interests of the clients; increase the propaganda of the platform, expand the public participation channels and promote the democratic openness of decision-making. Finally, improve the government information platform related system construction. Institutional rules and regulations that suit the development of government information platform should be formulated, such as information release system, personnel training system, work flow management system and accountability system for irregularities, which regulate the government affairs information through the binding and guidance of the system Platform development path to better enhance the capacity and level of public services.

\section{Conclusions}

Big data is helpful to promote social forces to participate in a wide range of political activities, enrich the communication channels between the government and the public, and strengthen supervision and reporting of government behaviors. Therefore, in the era of big data, these forces for promoting social change have made it an inevitable trend for the government to implement big data strategy and will surely promote the overall enhancement of government's public service capabilities. 


\section{References}

[1] Tao Peng. Big Data and Micro Era: Dual Construction of Virtual Social Public Service System [J]. Journal of Chongqing University of Posts and Telecommunications (Social Science Edition). 2015 (02) 50-78.

[2] Ding Li. Realization Problems and Perfecting Approaches to the Integration of E-government Information Resources under the Majorization Reform [J]. Modern Information Technology. 2014 (08).22-25.

[3] Zeng Baogen. Four-dimensional Conception of Innovation of Accountability Mechanism of Basic Public Service [J]. Zhongzhou University Press. 2013 (05) 62-67.

[4] Li Peng, Westbrook. Weibo government: micro-blog government information disclosure service [J]. Intelligence Theory and Practice. 2013 (02) 50-79.

[5] Liu Yeting, Wang Chunxiao. "Big Data" and New as an Analysis of Government's Transformation as a Model under the Background of "Big Data" [J]. 64-67. 